\title{
3D Laparoscopy: A Potential Cutting Edge in Minimal Invasive Digestive Surgery
}

\author{
Simone Sibio*, Sara di Carlo and Giuseppe S Sica \\ Department of Surgery, Italy \\ *Corresponding author: Simone Sibio, Department of Surgery, Italy
}

Submission: 眥 November 30, 2018 ; Published: 眥 December 04, 2018

\begin{abstract}
Laparoscopic surgery has changed surgical landscape, providing reduced surgical trauma, shorter hospital stays, less postoperative pain and better outcomes than open surgery. Since its first development in the 90's, 3D technology applied to laparoscopic surgery has had several technical improvements and now it represents, together with high definition technology, the best option in minimal invasive digestive surgery, providing shorter operative times and lower blood loss, making easier to perform surgical tasks both for trainees than for skilled surgeons. It remains a little bit more expensive than standard 2D laparoscopic devices but even cheaper than robotic equipment.
\end{abstract}

\section{Editorial}

Minimally invasive surgery has changed the way operations are performed. Since its advent in the early 1990s, laparoscopy has emerged as a catalyst of surgical renovation which rapidly has spread its application to the entire abdominal operations thanks to higher definition of graphic display, more visional comforts together with smaller incisions. The development of laparoscopic surgery has improved the outcome of patients by reducing surgical trauma, hospital stay, post-operative pain and allowing similar oncological results [1-8].

However, laparoscopy is more difficult to perform and to learn, mainly due to two-dimensional vision, lack of depth perception, little field of view, limited working space and impaired tactile feedback [9-13]. In 2D standard laparoscopy, the depth information loss is compensated by the surgeon experience and by the human brain ability to acquire secondary spatial depth landmarks during training and this explains the longer learning curves and training in laparoscopy $[13,14]$.

Laparoscopy with 3D imaging has existed as a tentative alternative solution for over 20 years. The camera system in modern 3D-laparoscopes consists of 2 adjacent cameras (bichannel), which simulates the stereopsis obtained from the fusion of the slightly different views from the binocular disparity of the 2 human eyes, known as stereoscopy. The result is a fusion of the 2 images, similar to the direct view of stereopsis, and is perceived as a single image with increased depth perception [15]. The initial 3D display was mainly based on Shutter Glass technique, which provided poor-definition images and was harmful to surgeons eyes and could cause side effects for the surgeon, such as headaches, dizziness, disorientation and physical discomfort.
3D laparoscope characterized by Film-type Patterned Retarder (FPR) was subsequently invented. This new generation of 3D laparoscopic facility features high definition and stable image, alleviating the visional burdens of surgical operators and truly bringing laparoscopic operations into a tridimensional era [16]. Therefore, Buchs et al. [11] firstly reported a smooth operation by FPR glasses in 2012, and from then on, 3D laparoscopy began globally popularized among surgeon communities.

The modern 3D technique is superior in an experimental setting. The experimental setting reported better performances (speed, accuracy) with 3D vision, both in the expert and in the novice surgeons [17]. To date, there have been few clinical trials as 3D platforms are poorly disseminated in surgical practices, mainly due to cost reasons, especially if compared with the uncertain advantages that this new technique could offer. Some of them take in account only experimental setting (task performing) while only very few focused-on results on the most common surgical digestive procedures [18].

Early comparative trials of 3D laparoscopic system vs 2D laparoscopy have shown contradictory results. Some trials indicated stereoscopy as being the main reason for better outcome, whereas other trials found no difference between the two optical systems. Several trials have criticized the poor quality and tolerance as the illumination was found to be suboptimal especially when standard 3D laparoscopy was compared with 2D laparoscopy with a higher resolution $[12,19]$. Since then, there has been an advancement in the technology of stereoscopy. The better illumination and resolution in the new generation 3D laparoscopy with HD resolution probably render the results from earlier 3D system obsolete. The results in 2 clinical trials showed either no difference or superiority for 3D 
laparoscopy with regards to performance time. The results for the experimental trials showed predominantly an improvement in time and a reduction in number of errors with 3D laparoscopy.

The experimental setting does not reflect the complexity of clinical conditions and this could explain why neither operative time nor decrease in errors were reported in other clinical trials [20]. However, results from our initial experience with $3 \mathrm{~d}$ laparoscopy on 95 patients ( 55 colorectal resections, 32 cholecystectomies, 5 gastrectomies, 3 distal pancreatectomies) showed that use of $3 \mathrm{~d}$ device in most common digestive surgical procedures carry shorter operative time and lower blood loss, although complications, hospital stay and conversion rates, as well as hospital expenses do not change by using $3 \mathrm{~d}$ rather than $2 \mathrm{~d}$ laparoscopy [21]. These results are confirmed by those of a recent large metanalysis including 21 studies (13 retrospective and 8 randomized trials) which analyzed existing experiences on several similar digestive surgical procedures (cholecystectomy, appendectomy, gastric resections, colorectal resections, hepatectomy, oesophagectomy) $[16,20,22,23]$.

As reported in available papers in literature, 3D vision seems to offer technical advantages in deep surgical fields, for vessel identification and ligation and in the accuracy of surgical manipulation as a result of the increased depth perception $[18,20,24]$. Currently, conclusive evidences that analyze the comparative efficacy of tridimensional laparoscopy remain in scarcity. Sorensen et al. [23] performed a systematic review of 3D laparoscopy vs 2D laparoscopy on simulated settings. Their results merely revealed a better performance on surgical tasks and trainings by tridimensional laparoscopy. By far, larger scale randomized trials on this topic are still lacking and no consensus has been reached among current literature. The main results, regarding comfort for the surgeon, have been investigated in simulated settings that have shown a better depth perception, hand-eyes coordination and accuracy.

The performances, in particular for novice surgeons, appear to be improved using 3D vision, with faster and more precise resolution of laparoscopic tasks [7,25-27] Sensation of neck and back pain, physical fatigue, nausea and dizziness have different rates between the clinical setting (in which they appear to be worse for 3D vision) and the simulated setting (in which they ameliorate for 3D vision), even if the worse results seem to be associated with earlier 3D systems [18]. Crosstalk and ghosting as a result of a non-optimal use of 3D visualization influences the laparoscopic performance and workload as shown by Sakata [28,29]. All these suggested that there is a need for further studies and investigation.

\section{Conclusion}

In conclusion, 3D technology has many perceived advantages and some limitations. The advantages include improving performance in minimally invasive surgery, offering stereoscopic depth and helping novice surgeons to orient themselves in the surgical landscape and complete complex tasks. This technology facilitates the recognition of diagnostically important shapes, alignment and anatomical features; increases anatomical appreciation for students with few visual spatial skills; and aids optical feedback. By contrast, the limitations of 3D visualization include its high cost and sporadic availability, the need for extra eyewear, operator dizziness and potential misperception. Despite these shortcomings, several studies shown that 3D vision quickens task completion mostly for more difficult tasks and that stereoscopic displays improve a novice's performance during the acquisition of minimally invasive surgical skills.

More randomized controlled clinical trials are obviously in need to confirm positive experimental results.

Taken together, in our experience, we believe that threedimensional laparoscopy is a preferably technical option against two-dimensional laparoscopy for digestive surgery. Thus, a wider clinical application of 3D laparoscopy could be warmly recommended. If 3D equipment reduces operating or training time for new surgeons, the equipment may be a worthwhile investment even if three dimensional devices remain more expensive than standard 2D equipment. Nevertheless, 3D laparoscopy is more affordable than robotic systems, which also provide 3D vision.

\section{References}

1. Kaiser AM (2014) Evolution and future of laparoscopic colorectal surgery. World J Gastroenterol 20: 15119-151124.

2. Sica GS, Biancone L (2013) Surgery for inflammatory bowel disease in the era of laparoscopy. World J Gastroenterol 19(16): 2445-2448.

3. Sica GS, Iaculli E, Biancone L, Di Carlo S, Scaramuzzo R, et al. (2011) Comparative study of laparoscopic vs open gastrectomy in gastric cancer management. Clinical trial World J Gastroenterol 17(41): 4602-4606.

4. Sica GS, Di Carlo S, Biancone L, Gentileschi P, Pallone F, et al. (2010) Single access laparoscopic ileocecal resection in complicated Crohn's disease. Surg Innov 17(4): 359-360.

5. Sica GS, Iaculli E, Benavoli D, Biancone L, Calabrese E, et al. (2008) Laparoscopic versus open ileo-colonic resection in Crohn's disease: shortand long-term results from a prospective longitudinal study. Clinical trial J Gastrointest Surg 12(6): 1094-1102.

6. Buchs NC, Morel P (2013) Three-dimensional laparoscopy: a new tool in the surgeon's armamentarium. Surg Technol Int 23:19-22.

7. Wagner OJ, Hagen M, Kurmann A, Horgan S, Candinas D, et al. (2012) Three-dimensional vision enhances task performance independently of the surgical method. Surg Endosc 26(10): 2961-2968.

8. Sahu D, Mathew MJ, Reddy PK (2014) 3D laparoscopy- help or hype; initial experience of a tertiary health centre. J Clin Diagn Res 8(7): NC01NC03.

9. Wilhelm D, Reiser S, Kohn N, Witte M, Leiner U, et al. (2014) Comparative evaluation of HD 2D/3D laparoscopic monitors and benchmarking to a theoretically ideal 3D pseudodisplay: even well-experienced laparoscopists perform better with 3D. Surg Endosc 28(8): 2387-2397.

10. Ohuchida K, Eishi N, Leiri S, Tomohiko A, Tetsuo I, et al. (2013) New advances in three-dimensional endoscopic surgery. J Gastroint Dig Syst 3: 152 .

11. Buchs NC, Volonte F, Pugin F, Toso C, Morel P (2013) Three-dimensional laparoscopy: a step toward advanced surgical navigation. Surg Endosc 27(2): 692-693.

12. Van Beurden MHPH, Ijsselsteijn WA, Juola JF (2012) Effectiveness of stereoscopic displays in medicine: a review 3D Res 3: 1-13. 
13. Way LW, Stewart L, Gantert W, Liu K, Lee CM, et al. (2003) Causes and prevention of laparoscopic bile duct injuries. Ann Surg 237(4): 460-469.

14. Lusc A, Bucur PL, Menhadji AD, Okhunov Z, Liss MA, et al. (2014) Evaluation of the impact of three-dimensional vision on laparoscopic performance. J Endourol 28(2): 261-266.

15. Smith R, Schwab K, Day A, Rockall T, Ballard K, et al. (2014) Effect of passive polarizing three-dimensional displays on surgical performance for experienced laparoscopic surgeons. Br J Surg 101(11): 1453-1459.

16. Cheng J, Gao J, Shuai X, Wang G, Tao K (2016) Two-dimensional versus three-dimensional laparoscopy in surgical efficacy: a systematic review and meta-analysis. Oncotarget 7(43): 70979-70990.

17. Buia A, Stockhausen F, Filmann N, Hanisch E (2017) 2D vs 3D imaging in laparoscopic surgery - results of a prospective randomized trial. Langenbecks Arch Surg 402(8): 1241-1253.

18. Vettoretto N, Foglia E, Ferrario L, Arezzo A, Cirocchi R, et al. (2018) Why laparoscopists may opt for three- dimensional view: a summary of the full HTA report on 3D versus 2D laparoscopy by S.I.C.E. (Società Italiana di Chirurgia Endoscopica e nuove tecnologie). Surgical Endoscopy 32(6): 2986-2993.

19. Mueller-Richter UD, Limberger A, Weber P, Spitzer W, Schilling M (2013) Comparison between three-dimensional presentation of endoscopic procedures with polarization glasses and an autostereoscopic display. Surg Endosc 17(3): 502-504

20. Fergo C, Burcharth J, Pommergaard HC, Kildebro N, Rosenberg J (2017) Three-dimensional laparoscopy vs 2-dimensional laparoscopy with high- definition technology for abdominal surgery: a systematic review. The American Journal of Surgery 213(1): 159-170.

21. Sibio S, Montagnese F, Giordano G, Efrati C, Mancuso A, et al. (2016) 3-D vs 2-D laparoscopic surgery for gastric and colorectal cancer: results of preliminary experience. Abstract presented at xx Congress of the European Society of Surgery, Naples, 16-17.

22. Komaei I, Navarra G, Currò G (2017) Three-dimensional versus two-dimensional laparoscopic cholecystectomy: a systematic review. J Laparoendosc Adv surg Tech A 27(8): 790-794.

23. Sørensen SM, Savran MM, Konge L, Bjerrum F (2016) Three-dimensional versus two-dimensional vision in laparoscopy: a systematic review. Surg Endosc 30(1): 11-23.

24. Alaraimi B, Bakbak E El, Sarker S, Makkiyah S, Al Marzouq A, et al. (2014) A randomized prospective study comparing acquisition of laparoscopic skills in three-dimensional (3D) vs two-dimensional (2D) laparoscopy. World J Surg 38(11): 2746-2752.

25. Smith R, Day A, Rockall T, Ballard K, Bailey M, et al. (2012) Advanved stereoscopic projection technology significantly improves novice performance of minimally invasive surgical skills. Surg Endosc 26(6): 15221527

26. Storz P, Buess GF, Kunert W, Kirschniak A (2012) 3D HD versus 2D HD: surgical task efficiency in standardized phantom tasks. Surg Endosc 26(5): 1454-1460.

27. Bilgen K, Ustun M, Karakahya M, Isik S, Sengul S, et al. (2013) Comparison of 3D imaging and 2D imaging for performance time of laparoscopic cholecystectomy. Surg Laparosc Endosc Percutan Tech 23(2): 180-183.

28. Sakata S, Grove PM, Hill A, Watson MO, Stevenson ARL (2016) The viewpoint-specific failure of modern 3D displays in laparoscopic surgery. Langenbecks Arch Surg 401(7): 1007-1018.

29. Sakata S, Grove PM, Watson MO, Stevenson ARL (2017) The impact of crosstalk on three-dimensional laparoscopic performance and workload. Surg Endosc 31(10): 4044-4050.
Creative Commons Attribution 4.0 International License

For possible submissions Click Here

\section{Submit Article}

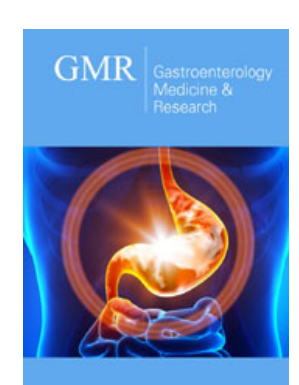

Gastroenterology Medicine \& Research

\section{Benefits of Publishing with us}

- High-level peer review and editorial services

- Freely accessible online immediately upon publication

- Authors retain the copyright to their work

- Licensing it under a Creative Commons license

- Visibility through different online platforms 